\title{
HUBUNGAN STATUS GIZI DENGAN KEJADIAN ANEMIA PADA IBU HAMIL DI PUSKESMAS KOTAGEDE II YOGYAKARTA
}

\author{
1Larasajeng Permata Sari, ${ }^{2}$ Sarwinanti, ${ }^{1}$ Sittti Nur Djannah \\ ${ }^{1}$ Fakultas Kesehatan Masyarakat, Universitas Ahmad Dahlan \\ ${ }^{2}$ Fakultas Ilmu Kesehatan Universitas 'Aisyiyah Yogyakarta \\ *Correspondence: larasajeng29@gmail.com.
}

Dikirim 07 Desember 2019; Diterima 10 Desember 2019; Dipublikasi Februari 2020

\begin{abstract}
Maternal deaths in Yogyakarta Special Region are caused by heart disease, bleeding, eclampsia, sepsis/infection. Bleeding is still number one causes of maternal death. Pregnancy with anemia are 5 times more at risk of bleeding than who are not. The aims of the research is to determine relationship of nutritional status with anemia in pregnant women in Kotagede II Yogyakarta Public Health Center. This was an observational analytic design and a cross sectional approach. The sampling method uses accidental sampling technique. The number of respondents was 77 pregnant women in second and third trimester. The research instrument used questionnaire sheets and medical records. Data were processed by Chi-Square statistical tests. Study found ( $p$ value) of nutritional status $=0.001$. The conclusion of this study is that there was a significant relationship between nutritional status with the incidence of anemia at Kotagede II Yogyakarta Health Center
\end{abstract}

Keyword : Anemia, Nutritional status, Pregnant women, Bleeding.

\section{PENDAHULUAN}

Sustainable Development Goals (SDGs) merupakan upaya pembangunan berkelanjutan yang menjadi acuan dalam kerangka pembanggunan dan perundingan negara-negara di dunia sebagai pengganti pembangunan global Millenium Development Goals (MDGs) yang telah berakhir di tahun 2015. SDGs memiliki beberapa tujuan, diantaranya menjamin kehidupan yang sehat dan mendorong kesejahteraan bagi semua orang di segala usia, dengan salah satu outputnya mengurangi Angka Kematian Ibu (AKI) hingga 70 per 100.000 kelahiran hidup $(\mathrm{KH})$ pada tahun 2030. Output ini tentunya semakin turun jika dibandingkan target MDGs tahun 2015 yaitu menurunkan AKI menjadi 102 per $100.000 \mathrm{KH}$ dalam kurun waktu 1990-2015 (1).

Menurut Dinkes DIY (2017), penyebab kematian ibu yang ditemukan di DIY disebabkan karena jantung, perdarahan, eklamsi, sepsis/infeksi, dll. Data tersebut dapat disimpulkan bahwa perdarahan masih menjadi penyebab kematian ibu. Anemia pada saat kehamilan merupakan penyebab dari perdarahan, ibu yang mengalami anemia pada saat kehamilan 5 kali lebih berisiko terjadinya perdarahan daripada ibu yang tidak anemia pada saat kehamilan.

Hasil penelitian Fakultas Kedokteran di seluruh Indonesia pada tahun 2016 menunjukkan bahwa prevalensi anemia ibu hamil di Indonesia adalah 50-63\%. Sementara itu, prevalensi anemia ibu hamil di DIY pada tahun 2015 sebesar 14,85\% dan mengalami kenaikan pada tahun 2016 yaitu sebesar 16,09 \% dan kembali turun menjadi 14,32 pada tahun 2017. Upaya menurunkan prevalensi anemia ibu hamil harus lebih dilakukan secara optimal mengingat target penurunan jumlah kematian ibu menjadi prioritas permasalahan kesehatan di DIY. Ibu hamil dengan anemia di Kabupaten Kulonprogo 12,88, Bantul 16,32, Gunung Kidul 16,77, Sleman 8,06, Yogyakarta 30,81 (1).

Peran pemerintah dalam menangani kejadian anemia pada ibu hamil yaitu dengan memberikan tambah darah minimal 90 tablet selama kehamilan (Kemenkes 
RI, 2017). Berbagai kebijakan dan program-program yang ada seperti Upaya Perbaikan Gizi Keluarga (UPGK), Keluarga sadar gizi (KADARZI), pemberian makanan tambahan bagi anak sekolah dan lainnya. Hasil PSG (Pemantauan Status Gizi) 2016 mendapatkan hanya 40,2\% ibu hamil yang mendapatkan TTD minimal 90 tablet lebih rendah dari target nasional tahun 2016 sebesar 85\% (2).

Untuk meningkatkan kepedulian masyarakat dengan adanya kematian ibu terhadap kejadian anemia, Bidan mengajak masyarakat untuk mendukung upaya perbaikan gizi pada ibu hamil dengan pemberian tablet penambah darah, makan yang bergizi dan melakukan pemeriksaan rutin. Anemia pada ibu hamil, yang merupakan salah satu faktor risiko kematian ibu, terjadi karena ibu hamil mengalami defisiensi zat besi. Oleh karena itu, pemberian tablet tambah darah diharapkan mampu mengurangi kasus anemia pada ibu hamil yang pada akhirnya akan menurunkan risiko kematian ibu (3).

Zat besi merupakan mineral yang dibutuhkan tubuh untuk membentuk sel darah merah (haemoglobin). Anemia dalam kehamilan menyebabkan ibu tidak mampu menghadapi kehilangan darah dan membuatnya lebih rentan terhadap infeksi. Anemia juga dapat menimbulkan hipoksia fetal, persalinan premature dan pengaruh terhadap kematian ibu (4).

Berdasarkan hasil studi pendahuluan yang telah dilakukan pada tanggal 5 Desember 2018 di Puskesmas Kotagede II terdapat 1024 orang ibu hamil yang melakukan kunjungan pada tahun 2018 namun terdapat 328 orang yang mengalami anemia. Mengingat pentingnya akibat yang bisa timbul oleh anemia selama kehamilan, maka penulis tertarik untuk meneliti tentang "Hubungan Status Gizi dengan Kejadian Anemia pada Ibu Hamil di Puskesmas Kotagede II Yogyakarta”.

\section{METODE PENELITIAN}

Jenis penelitian kuantitatif dengan studi korelasi yaitu suatu penelitian untuk mengetahui ada tidaknya hubungan antara status gizi dengan kejadian anemia pada Ibu hamil di Puskesmas Kotagede II Yogyakarta. Penelitian ini menggunakan survey korelasional.

Uji validitas dilakukan pada tanggal 28 Januari 2019 di Puskesmas Kotagede I Yogyakarta dengan responden trimester II dan trimester III. Sample berjumlah 77 orang. Teknik pengambilan sample adalah accidental sampling. Data dianalisis dengan menggunakan uji chi square.

\section{HASIL DAN PEMBAHASAN}

Penelitian ini dilakukan di Puskesmas Kotagede II Yogyakarta dengan jumlah sampel $77 \mathrm{ibu}$ hamil trimester II dan trimester III. Data primer diperoleh dengan melakukan pemeriksaan LILA. Data sekunder menggunakan rekam medis.

Tabel 1. Distribusi Frekuensi Kejadian Anemia pada Ibu Hamil di Puskesmas Kotagede II Yogyakarta

\begin{tabular}{lcc}
\hline \multicolumn{1}{c}{ Variabel } & Frekuensi & Presentase \\
\hline Kejadian Anemia & & \\
a. Anemia & 28 & $36,3 \%$ \\
b. Tidak Anemia & 49 & $63,7 \%$ \\
Status Gizi & & \\
a. KEK & 13 & $16,9 \%$ \\
b. Tidak KEK & 64 & $83,1 \%$ \\
\hline
\end{tabular}

Sumber: Data Primer 2019

Berdasarkan tabel 1 diketahui bahwa ibu hamil yang tidak anemia lebih banyak yaitu $63,7 \%$, dibandingkan ibu hamil yang mengalami anemia. Sedangkan status gizi ibu hamil yang tidak mengalami KEK lebih besar yaitu sebanyak 83,1\%, dibandingkan dengan ibu hamil yang mengalami KEK. 
Tabel 2. Distribusi Frekuensi Hubungan Status Gizi dengan Kejadian Anemia pada Ibu Hamil di Puskesmas Kotagede II Yogtakarta

\begin{tabular}{|c|c|c|c|c|c|c|c|}
\hline \multirow{3}{*}{ Status gizi } & \multicolumn{4}{|c|}{ Kejadian Anemia } & \multirow{2}{*}{\multicolumn{2}{|c|}{ Jumlah }} & \multirow{3}{*}{$\begin{array}{l}\text { Nilai } \\
p\end{array}$} \\
\hline & \multicolumn{2}{|c|}{ Tidak Anemia } & \multicolumn{2}{|c|}{ Anemia } & & & \\
\hline & $\mathrm{F}$ & $\%$ & $\mathrm{~F}$ & $\%$ & $\mathrm{~F}$ & $\%$ & \\
\hline a. KEK & 3 & $3,9 \%$ & 10 & $13 \%$ & 13 & $16,9 \%$ & 001 \\
\hline b. Tidak KEK & 46 & $59,8 \%$ & 18 & $23,3 \%$ & 64 & $83,1 \%$ & 0,001 \\
\hline
\end{tabular}

Sumber: Data Primer 2019

Berdasarkan tabel 2, dari 13 responden dengan status gizi KEK (Lila $\leq 23,5 \mathrm{~cm}$ ) terdapat $13 \%$ yang anemia dan $3,9 \%$ tidak anemia. Sedangkan 64 responden dengan status gizi tidak KEK (Lila $>23,5 \mathrm{~cm}$ ) terdapat 18 (23,3\%) yang anemia dan 46 $(59,8 \%)$ tidak anemia. Berdasarkan uji Chi Square, pada bagian Pearson chi-square terlihat nilai value $0,001(<0,05)$ maka dapat disimpulkan terdapat hubungan signifikan status gizi dengan kejadian anemia pada ibu hamil di Puskesmas Kotagede II Yogyakarta. Ibu hamil yang kekurangan gizi atau nutrisi juga berpengaruh buruk terhadap pertumbuhan janin yang dikandungnya.

Dalam penelitian ini ada 77 responden dimana didapatkan bahwa kejadian anemia yang dialami ibu hamil di Puskesmas Kotagede II sejumlah 28 orang (36,3\%) ibu hamil, sedangkan yang tidak anemia sebanyak 49 orang (63,7\%). Anemia menjadi faktor resiko terjadi perdarahan. Adanya perdarahan pasca persalinan antara lain karena gangguan rahim, pelepasan plasenta, robekan jalan lahir dan gangguan faktor pembekuan darah, resiko akan meningkat antara lain pada ibu yang menderita anemia dan Rahim teregang terlalu besar karena bayi besar (5).

Anemia dalam kehamilan memberi pengaruh kurang baik bagi ibu, baik dalam kehamilan, persalinan, maupun nifas dan masa selanjutnya. Penyulit-penyulit yang dapat timbul akibat anemia adalah keguguran (abortus), kelainan premature, persalinan yang lama akibat otot Rahim di dalam berkontraksi (inersia uteri), syok, infeksi baik saat bersalin maupun pasca bersalin serta anemia yang berat $(<4 \mathrm{gr} \%$ dapat menyebabkan dekompensasi kordis, hipoksia akibat anemia dapat menyebabkan syok dan kematian ibu pada persalinan (4).

Anemia defisiensi besi adalah anemia yang terjadi akibat kekurangan zat besi dalam darah. Pengobatanya adalah pemberian tablet besi yaitu keperluan zat besi untuk wanita hamil, tidak hamil dan dalam laktasi yang dianjurkan. Untuk menegakan diagnose anemia defisiensi besi dapat didapatkan keluhan cepat lelah, sering pusing, mata berkunang-kunang dan keluhan mual muntah pada ibu hamil muda. Pada pemeriksaan dan pengawasan $\mathrm{Hb}$ dapat dilakukan dengan menggunkan metode sahli, dilakukan minimal 2 kali selam trimester I dan III (6)

Pengaruh dan bahaya anemia kehamilan pada masa antenatal adalah berat badan kurang, plasenta previa, eklamsia, KPD, sedangkan pada intratal mengakibatkan tenaga untuk mengedan tidak kuat, perdarahan intranatal, syok, dan masa pascanatal dapat terjadi subinvolusi. Sedangkan pada neonatus dapat terjadi premature, apgar score rendah, gawat janin. Keseimbangan zat besi dalam tubuh perlu mendapatkan perhatian karena banyaknya zat besi yang dibutuhkan sama dengan banyaknya zat besi yang dikeluarkan, zat besi yang dikeluarkan harus diganti oleh zat besi yang diserap dari makanan (7).

Berdasarkan hasil penelitian yang didapatkan menggunakan uji chi square didapatkan pada bagian person chi-square terlihat nilai Asymp. Sig 0,001 < 0,05, maka dapat disimpulkan terdapat hubungan yang signifikan terhadap status gizi ibu dengan kejadian anemia di Puskesmas Kotagede II dengan kejadian anemia pada umur yang KEK sejumlah 10 orang (13\%), sedangkan umur ibu yang tidak beresiko sejumlah 18 orang (23,3\%).

Salah satu cara untuk mengukur status gizi pada ibu hamil dengan melakukan pemeriksaan LILA. Pengukuran ini dapat bermanfaat untuk mengetahui keadaan status gizi ibu hamil serta mendeteksi apakah ibu hamil menderita KEK (Kurang Energi Kronik). Pengukuran Lila pada ibu hamil adalah untuk mendeteksi resiko terjadinya kejadian bayi dengan BBLR. Resiko KEK untuk ibu hamil adalah apabila Lila $<23.5 \mathrm{~cm}(8)$ Responden yang pola makan tidak sehat akan lebih beresiko 
mengalami anemia daripada orang yang pola makan sehat. Hal ini karena salah satu penyebab anemia adalah defisiensi zat besi karena pola makan tidak sehat dan pengaturan jumlah dan jenis yang tidak sesuai dengan gizi seimbang ibu hamil (9)

Penelitian ini sesuai dengan teori Ismaini (2016) menyatakan bahwa hubungan status gizi berpengaruh terhadap kejadian anemia. Status gizi juga didefinisikan sebagai status kesehatan yang dihasilkan oleh keseimbangan antara kebutuhan dan masukan nutrient dan merupakan kebutuhan pokok untuk ibu hamil (10).

Ibu dengan kondisi kekurangan nutrisi berisiko persalinan sulit atau lama, melahirkan bayi dalam kondisi premature (lahir belum cukup bulan), terjadinya perdarahan pada ibu sesudah melahirkan dan biasanya saat persalinan ibu juga kekurangan tenaga untuk mengejan saat terjadinya proses persalinan sehingga melahirkan dengan cara operasi cenderung tinggi bagi ibu hamil kurang nutrisi (11). Terdapat 41\% (20 juta) ibu hamil menderita kekurangan gizi, timbulnya masalah gizi pada ibu hamil, seperti kejadian KEK, tidak terlepas dari keadaan sosial, ekonomi, biososial dari ibu hamil dan keluarganya seperti pendidikan, tingkat pendapatan, konsusmsi pangan, umur, paritas dan sebagainya. Kekurangan gizi dapat menyebabkan ibu menderita anemia, suplai darah yang mengantarkan oksigen dan makanan pada janin akan terhambat, sehingga janin akan mengalami gangguan pertumbuhan dan perkembangan. Oleh karena itu pemantauan gizi ibu hamil sangatlah penting dilakukan (12).

Gizi dan Nutrisi ibu hamil merupakan hal penting yang harus dipenuhi selama kehamilan berlangsung. Nutrisi dan gizi yang baik ketika kehamilan sangat membantu ibu hamil dan janin tetap sehat. Status gizi merupakan status kesehatan yang dihasilkan oleh keseimbangan antara hubungan dan masukan nutrisi. Gizi ibu hamil adalah makanan sehat dan seimbang yang harus dikonsumsi selama kehamilan yaitu dengan porsi dua kali makan orang yang tidak hamil. Kebutuhan gizi pada masa kehamilan akan meningkat sebesar 15\% dibandingkan dengan kebutuhan wanita normal. Peningkatan gizi ini dibutuhkan untuk pertumbuhan rahim (uterus), payudara (mammae), volume darah, plasenta, air ketuban dan pertumbuhan janin (13).

Pola makan ibu selama masa kehamilannya membutuhkan tambahantambahan zat besi dan tambahan multivitamin, kebutuhannya akan zat besi hampir dua kali lipat. Untuk mendapatkan lebih banyak manfaat zat besi ibu harus banyak konsumsi sayuran, seperti buncis, artichoke, dan kacang merah, serta mengkombinasikan dengan makananmakanan yang mengandung vitamin $\mathrm{C}$, seperti buah-buahan sitrusg, brokoli, paprika, maupun stroberi. Hal ini disebabkan zat besi yang berasal dari tumbuhan tidak diserap seefektif kandungan zat besi dari daging merah, ikan, dan daging unggas. Sehingga ibu membutuhkan vitamin C yang berfungsi menyerap mineral ini (14).

Banyak literatur kuantitatif saat ini menunjukkan bahwa kunci untuk mempertahankan kehamilan yang sehat dan pencegahan utama komplikasi ibujanin adalah untuk membangun kebiasaan diet yang sehat (Lucas, Charlton, \& Yeatman, 2014; Girard \& Olude, 2012) .Dalam meta analisis menilai saran gizi selama kehamilan, konseling gizi diidentifikasi sebagai intervensi yang paling mungkin memiliki peningkatan keseluruhan pada pengetahuan ibu tentang gizi dan asupan makanan selama kehamilan (15)

\section{KESIMPULAN DAN SARAN}

Berdasarkan hasil penelitian dan pembahasan tentang faktor-faktor yang mempengaruhi kejadian anemia pada ibu hamil di Puskesmas Kotagede II Yogyakarta, maka dapat diambil kesimpulan sebagai berikut, yaitu Ibu hamil di Puskesmas Kotagede II yang mengalami anemia sebesar 28 orang (36,3\%). Terdapat hubungan bermakna antara status gizi dengan kejadian anemia ibu hamil di Puskesmas Kotagede II Yogyakarta. Maka dapat disimpulkan bahwa status gizi pada ibu hamil mempengaruhi kejadian anemia. Universitas 'Aisyiyah Yogyakarta dan Universitas Ahmad Dahlan diharapkan untuk menambah referensi buku khususnya tentang anemia pada kehamilan.

Diharapkan pada ibu hamil untuk patuh dalam mengkonsumsi tablet tambah darah, memperhatikan asupan nutrisi yang dikonsumsi, serta memahami faktor risiko anemia berdasarkan usia yang beresiko dan umur kehamilan di setiap 
trimester untuk menghindari kejadian anemia pada kehamilan .Bagi bidan Puskesmas Kotagede II Yogyakarta untuk lebih memperhatikan pada ibu hamil yang beresiko anemia dengan melihat buku register untuk memberikan peanganan dengan memberikan biskuit ibu hamil sesuai program pemerintah untuk ibu dengan KEK, dan memberikan konseling untuk mencegah anemia.

\section{REFERENSI :}

1. Kementerian Kesehatan RI Badan Penelitian dan Pengembangan. Hasil Utama Riset Kesehatan Dasar. Kementrian Kesehat Republik Indones [Internet]. 2018;1100. Available from: http://www.depkes.go.id

2. Rahmawati. Asuhan Kebidanan. Jakarta: Victory Inti Cipta; 2011.

3. Dinkes DIY. Profil Kesehatan Provinsi Daerah Istimewa Yogyakarta Tahun 2017. Dinas Kesehat DIY [Internet]. 2017;1-224. Available from: http://www.depkes.go.id

4. Proverawati. Anemia dan Anemia Kehamilan. Yogyakarta: Nuha Medika; 2011.

5. Hermiyanti. Kebijakan Operasional Percepatan Penurunan Angka Kematian. In Direktur Bina Kesehatan Ibu Ditjen Kesmas; 2010.

6. Purwaningtyas ML, Prameswari GN. Faktor Kejadian Anemia Pada Ibu Hamil. Higeia J Public Heal Res Dev. 2017;1(3):43-54.

7. Manuaba. Ilmu Kebidanan, Penyakit Kandungan dan KB. Jakarta: EGC; 2010.

8. Dina Mariana DW. Hubungan Pola Makan dengan Kejadian Anemia pada Ibu Hamil di Wilayah Kerja Puskesmas Bengkulu. J Keperawatan Silampari. 2018;1.

9. Astuti. Faktor-Faktor yang Berhubungan dengan Kejadian Anemia Gizi pada Ibu Hamil di Puskesmas Jalaksana Kuningan. J Kesehat. 2010;6.

10. Ismaini. Hubungan Status Gizi dengan Kejadian Anemia pada Ibu hamil Trimester III di Puskesmas Paliyan Gunungkidul. Naskah Publ. 2017;

11. Lubis. Status Gizi Ibu Hamil Serta Pengaruhnya Terhadap Bayi Yang Dilahirkan. 2008;

12. Amiruddin. Asupan Gizi pada Ibu Hamil. Yogyakarta: Nuha Medika; 2009.

13. Dewi A. Gizi pada Ibu Hamil. Artik Kesehat. 2016;

14. Sulistyoningsih H. Gizi untuk Kesehatan Ibu dan Anak. Yogyakarta: Graha Ilmu; 2011.

15. Lucas C, Charlton KE, Yeatman H. Nutrition Advice During Pregnancy: Do Women Receive it and Can Health Professionals Provide it? Matern Child Health J. 2014;18(10):2465-78. 